\title{
Thermal Properties of Methane Gas Hydrates
}

\section{Introduction}

Gas hydrates are crystalline solids in which molecules of a "guest" species occupy and stabilize cages formed by water molecules. Similar to ice in appearance (fig. 1), gas hydrates are stable at high pressures and temperatures above freezing $\left(0^{\circ} \mathrm{C}\right)$. Methane is the most common naturally occurring hydrate guest species. Methane hydrates, also called simply "gas hydrates," are extremely concentrated stores of methane and are found in shallow permafrost and continental margin sediments worldwide. Brought to sea-level conditions, methane hydrate breaks down and releases up to 160 times its own volume in methane gas.

The methane stored in gas hydrates is of interest and concern to policy makers as a potential alternative energy resource and as a potent greenhouse gas that could be released from sediments to the atmosphere and ocean during global warming. In continental margin settings, methane release from gas hydrates also is a potential geohazard and could cause submarine landslides that endanger offshore infrastructure.

Gas hydrate stability is sensitive to temperature changes. To understand methane release from gas hydrate, the U.S. Geological Survey (USGS) conducted a laboratory investigation of pure methane hydrate thermal properties at conditions relevant to accumulations of naturally occurring methane hydrate. Prior to this work, thermal properties for gas hydrates generally were measured on analog systems such as ice and non-methane hydrates or at temperatures below freezing; these conditions limit direct comparisons to methane hydrates in marine and permafrost sediment.

Three thermal properties, defined succinctly by Briaud and Chaouch (1997), are estimated from the experiments described here:

- Thermal conductivity, $\lambda$ : if $\lambda$ is high, heat travels easily through the material.

- Thermal diffusivity, $\kappa$ : if $\kappa$ is high, it takes little time for the temperature to rise in the material.

- Specific heat, $c_{p}$ : if $c_{p}$ is high, it takes a great deal of heat to raise the temperature of the material.

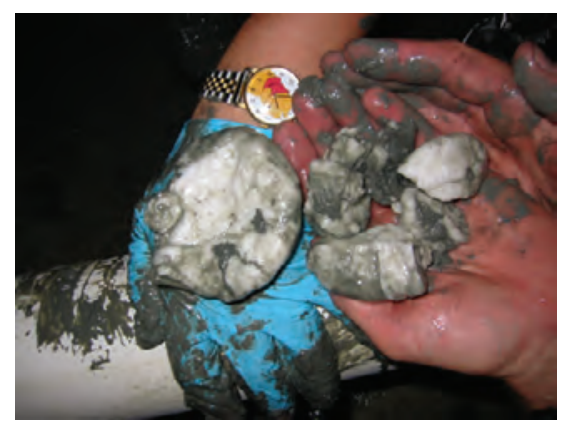

Figure 1. Sample of methane hydrate from the Gulf of Mexico.

Methane hydrates can look like ice or packed snow but break down at atmospheric conditions, releasing nearly 160 times their own volume of methane gas. (Photograph by W.J. Winters, U.S. Geological Survey)

\section{Measurements of Thermal Properties}

Thermal properties of pure methane hydrate were studied in the laboratory. The formation technique uses a highly reproducible method developed by USGS (Stern and others, $2000,1996)$ in which granular ice is packed into the sample chamber of a pressure vessel (fig. 2A). The vessel is then pressurized with methane gas, slowly heated to allow the ice to convert to hydrate, and finally compressed to compact the methane hydrate around the centrally located thermal probe.

Thermal properties were measured by warming the sample with a heater wire in the thermal probe while measuring the temperature change with a centrally located thermal sensor (fig. 2A). The temperature change is linear when plotted as a function of the natural logarithm (ln) of time, as shown by the overlapping blue circles plotting every tenth data point in figure 2B. The sample's thermal properties are calculated from the slope and intercept of the straight-line fit through the data (A and B, respectively, along the green line in fig. 2B) (Waite and others, 2006). These measurements are repeated over a range of pressures and temperatures.

\section{Thermal Property Results}

Equations for calculating thermal conductivity, thermal diffusivity, and specific heat in methane hydrate are given in table 1 (Waite and others, 2007).

Measurements of thermal properties are used in models that can predict changes that methane hydrates undergo during their recovery as a resource or their potential dissociation during warming. Because hydrates displace either ice (permafrost settings) or water (marine settings or beneath permafrost),

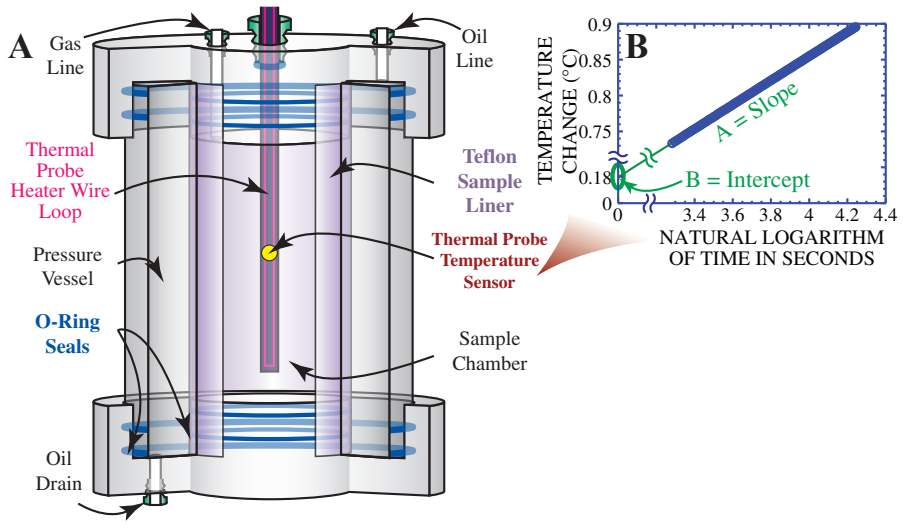

Figure 2. (A) Schematic diagram of the thermal properties pressure vessel. Cylindrical hydrate samples that are $13.3 \mathrm{~cm}$ long by $4.1 \mathrm{~cm}$ in diameter are formed around a needle probe (enlarged to show detail). $(B)$ Thermal properties are estimated from the slope and intercept of the straight-line fit (green line) to the sample's temperature change in response to heat from the heater wire (overlapping blue circles, showing every tenth data point). 
Table 1. Equations for estimating thermal properties of methane gas hydrate (Waite and others, 2007).

[MPa, million pascals; psi, pounds per square inch; $\lambda$, thermal conductivity; $\kappa$, thermal diffusivity; $\mathrm{c}_{\mathrm{p}}$, specific heat; $\mathrm{W}$, watts; $\mathrm{m}$, meters; T, temperature; ${ }^{\circ} \mathrm{C}$, degrees Celsius; K, Kelvin; ${ }^{\circ} \mathrm{F}$, degrees Fahrenheit; s, seconds; J, joules; $\mathrm{kg}$, kilograms; P, pressure]

\begin{tabular}{|c|c|}
\hline \multicolumn{2}{|l|}{ Thermal property fit equations } \\
\hline $\begin{array}{c}\text { Temperature dependence } \\
\text { (Pressure held at } 31.5 \mathrm{MPa}, 4,570 \mathrm{psi} \text { ) }\end{array}$ & $\begin{array}{l}\text { Temperature } \\
\text { range }\end{array}$ \\
\hline$\lambda(\mathrm{W} / \mathrm{m} \cdot \mathrm{K})=-(2.78 \pm 0.05) \cdot 10^{-4} \cdot \mathrm{T}\left({ }^{\circ} \mathrm{C}\right)+(0.62 \pm 0.02)$ & $-20-17^{\circ} \mathrm{C}$ \\
\hline${ }^{*} \kappa\left(\mathrm{m}^{2} / \mathrm{s}\right)=(5.04 \pm 0.02) \cdot 10^{-5} / \mathrm{T}(\mathrm{K})+(1.25 \pm 0.05) \cdot 10^{-7}$ & $\begin{array}{c}1-17^{\circ} \mathrm{C} \\
(274-290 \mathrm{~K})\end{array}$ \\
\hline $\mathrm{c}_{\mathrm{p}}(\mathrm{J} / \mathrm{kg} \cdot \mathrm{K})=(6.1 \pm 0.3) \cdot \mathrm{T}\left({ }^{\circ} \mathrm{C}\right)+(2,160 \pm 100)$ & $1-17^{\circ} \mathrm{C}$ \\
\hline $\begin{array}{c}\text { Pressure dependence } \\
\text { (Temperature held at } 14.4^{\circ} \mathrm{C}, 58^{\circ} \mathrm{F} \text { ) }\end{array}$ & \\
\hline$\lambda(\mathrm{W} / \mathrm{m} \cdot \mathrm{K})=(2.54 \pm 0.06) \cdot 10^{-4} \cdot \mathrm{P}(\mathrm{MPa})+(0.61 \pm 0.02)$ & \\
\hline$\kappa\left(\mathrm{m}^{2} / \mathrm{s}\right)=(2.87 \pm 0.08) \cdot 10^{-10} \cdot \mathrm{P}(\mathrm{MPa})+(3.1 \pm 0.2) \cdot 10^{-7}$ & \\
\hline $\mathrm{c}_{\mathrm{p}}(\mathrm{J} / \mathrm{kg} \cdot \mathrm{K})=(3.30 \pm 0.06) \cdot \mathrm{P}(\mathrm{MPa})+(2,140 \pm 100)$ & \\
\hline
\end{tabular}

${ }^{*}$ The $\mathrm{T}^{-1}$ dependence of the $\kappa$ fit requires input temperatures in Kelvin.

comparing thermal properties of methane hydrate to those of ice and water helps gauge the extent to which a host sediment's thermal properties are altered by the presence of methane hydrate.

- Thermal conductivity, $\lambda$ : The thermal conductivity of water is approximately equal to that of methane hydrate, so the thermal conductivity beneath permafrost or in marine settings is essentially independent of methane hydrate content. Methane hydrate is generally found in abundance below, rather than in, permafrost, but the presence of methane hydrates in ice-dominated permafrost can measurably increase the geothermal gradient because the thermal conductivity of ice is approximately four times that of methane hydrate.

- Thermal diffusivity, $\kappa$ : Because the thermal diffusivity of water is about half that of methane hydrate, hydrate-bearing sediment can change temperature more rapidly than waterbearing sediment. This characteristic presents a potential geohazard for petroleum production from deepwater production sites overlain by hydrate-bearing layers (fig. 3). If high-temperature hydrocarbons in the wellbore dissociate hydrate in the surrounding sediment, the strength of the sediment decreases, potentially causing well failure or localized submarine landslides.

- Specific heat, $c_{p}$ : Hydrate breakdown is an endothermic process, absorbing heat while the surrounding sediment cools. Because the specific heat of methane hydrates is about half that of water, hydrate-bearing sediment stores less heat which can then be made available to help fuel dissociation. When estimating the efficiency of hydrate dissociation, neglecting the reduced contribution of methane hydrates to the host sediment's specific heat results in an overestimate of the dissociation rate and, hence, the methane production rate.

\section{Conclusions}

The presence of methane gas hydrates can alter the thermal properties of host sediments. Laboratory efforts by the USGS to measure thermal properties of pure methane gas hydrates

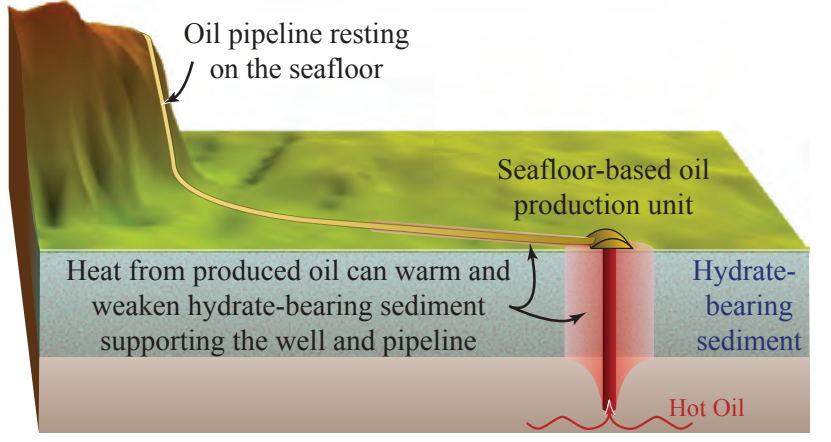

Figure 3. Petroleum recovery brings high-temperature fluids up through cool gas hydrate-bearing sediment (blue region), heating the sediment (red overlay). The high thermal diffusivity of gas hydrate accelerates the heating rate in the surrounding sediment. Gas hydrate breakdown can destabilize the host sediment and lead to well failure. Warm pipelines also must be routed to avoid regions of outcropping or surficial gas hydrates.

support field, modeling, and other laboratory studies by providing a numerical basis for predicting the thermal response of hydrate-bearing sediment to changes induced naturally or through human action.

\section{References}

Briaud, J.L., and Chaouch, A., 1997, Hydrate melting in soil around hot conductor: Journal of Geotechnical and Geoenvironmental Engineering, v. 123, p. 645-653.

Stern, L., Kirby, S., Durham, W., Circone, S., and Waite, W.F., 2000, Laboratory synthesis of pure methane hydrate suitable for measurement of physical properties and decomposition behavior, in Natural gas hydrate in oceanic and permafrost environments, edited by M.D. Max: Kluwer Academic Publishers, Netherlands, p. 323-348.

Stern, L.A., Kirby, S.H., and Durham, W.B., 1996, Peculiarities of methane clathrate hydrate formation and solid-state deformation, including possible superheating of water ice: Science, v. 273, p. 1843-1848.

Waite, W.F., Gilbert, L.Y., Winters, W.J., and Mason, D.H., 2006, Estimating thermal diffusivity and specific heat from needle probe thermal conductivity data: Review of Scientific Instruments, v. 77, 044904, doi:10.1063/1.2194481.

Waite, W.F., Stern, L.A., Kirby, S.H., Winters, W.J., and Mason, D.H., 2007, Simultaneous determination of thermal conductivity, thermal diffusivity and specific heat in sI methane hydrate: Geophysical Journal International, v. 169, p. 767-774, doi:10.1111/j.1365-246X.2007.03382.x.

\section{By William F. Waite}

For more information, please contact:

William F. Waite

U.S. Geological Survey

384 Woods Hole Road

Woods Hole, MA 02543

Telephone: $508-457-2346$

E-mail: wwaite@usgs.gov

http://energy.usgs.gov/other/gashydrates/ 